\title{
Neuropsychological Profile of Juvenile Delinquents
}

\author{
Swastik N Sahoo ${ }^{1 *}$, Ruchi Srivastava ${ }^{2}$, Divya Baveja ${ }^{3}$
}

\section{ABSTRACT}

Introduction: The relation between the occurrence of criminal behaviour and brain dysfunction were studied extensively and available literature was reviewed. Aim: To study the neuropsychological profile of juvenile delinquents. Method: 15 cases who have committed repeated offences, between age group 10 to 14 of the male gender with minimum primary education were selected using Purposive sampling technique. Tools: They were screened through the Diagnostic Test of Learning Disability, Coloured Progressive Matrices/ Standard progressive Matrices and Brief Psychiatric Rating Scale for Children. Samples with IQ below sub-average, learning disability or any kind of psychopathology were excluded from the study. AIIMS neuropsychological battery was administered as the main tool to assess the neuropsychological functioning of the delinquents. Result: Findings suggest that the organicity was found in 12 cases with specific areas. Implication: The results of the current research are helpful in planning intervention and rehabilitation program for juvenile delinquents.

Keywords: Neuropsychological profiling, Recidivism, Organicity, Psychopathology, Juvenile Delinquents

$\mathrm{N}$ europsychology seeks to understand the functioning of brain and its relation with the observable behavior (Beamount, 2008). Neuropsychological profile is characterized by deficits in specific areas including memory and learning, working memory, executive functions, attention and processing speed (Reichenberg, 2010).

Neuropsychological methods have been applied to study the delinquent behavior of juveniles. Any type of head injury or acquired brain disease is not presumed to be sole origin of the hypothesized cognitive dysfunctions of delinquents. There might be number of possibilities involved including the disruptions in fetal brain development, early exposure to neurotoxins, early environmental deprivations, fluctuating neurochemical states and heritable individual variations in brain.

The aim of neuropsychological research on delinquency is to identify individuals whose neuropsychological dysfunctions place them at risk for maladaptive behavioral response to

${ }^{1}$ Amity Institute of Behavioral and Allied Sciences, Amity University, Lucknow, Uttar Pradesh, India.

${ }^{2}$ Amity Institute of Behavioral and Allied Sciences, Amity University, Lucknow, Uttar Pradesh, India.

${ }^{3}$ Amity Institute of Behavioral and Allied Sciences, Amity University, Lucknow, Uttar Pradesh, India.

*Corresponding Author

Received: March 05, 2021; Revision Received: April 01, 2021; Accepted: April 25, 2021

(C) 2021, Sahoo S. N., Srivastava R. \& Baveja D.; licensee IJIP. This is an Open Access Research distributed under the terms of the Creative Commons Attribution License (www.creativecommons.org/licenses/by/2.0), which permits unrestricted use, distribution, and reproduction in any Medium, provided the original work is properly cited. 


\section{Neuropsychological Profile of Juvenile Delinquents}

environmental influences. Behavior responses can differ from individual to individual on the basis of their needs, demands and exposure to their environment. However, these individuals cannot rationalize their thought and cannot control their impulses which create the maladaptive behavior responses and acts which are converted into crime that is not socially acceptable.

Frontal lobe of the human brain controls systems that implement a variety of different behavior strategies in response to the environment which includes planning, self-awareness, regulation of behavior, attention, concentration, working memory, reasoning, cognitive flexibility, inhibitory control and problem solving which is collectively known as executive functioning. Due to such impairments in executive functioning, there is a chance of maladaptive behavior response which further leads to risk of involving in crime.

Johnson, Kemp, Heard, Lennings and Hickie (2015) in their study investigated whether youths with childhood-onset antisocial behaviour have higher rates of psychiatric illness, neuropsychological and psychosocial dysfunctions than youths who engage in antisocial behaviour for the first time in adolescence. The childhood-onset group displayed deficits in verbal learning and memory, higher rates of psychosis, childhood maltreatment and more serious violent behaviour.

Tung and Chhabra (2009) in their study attempted to differentiate the delinquents from the non-delinquents on the basis of the most commonly and clinically used neuropsychological measures so that early identification of neuropsychological parameters in children can prevent delinquent outcomes. The sample consisted of 40 delinquent boys taken from an observation home situated in Ludhiana in the state of Punjab, India, 40 non-delinquent boys attending a normal school. Significant group differences were found on nonverbal intelligence, visual motor performances and language function.

Investigations have been conducted to identify variables with juvenile delinquency, several factors associated with poor parenting skills in the households, family criminal history, socioeconomic status and academic achievement levels which overview the risk factors found to be associated with juvenile delinquency. Other factors such as intellectual functioning which have a causal link between intelligent quotient and the juvenile delinquency. The neuropsychologist who is interested in delinquency tries to understand the ways in which the individual differences in neuropsychological abilities interact with social and environmental conditions to increase the chances that delinquent acts will occur (Moffit \& Henry, 1991).

Innumerable researches have been conducted to understand the factors that determine crime behaviour but very few are done to understand the role of the brain in the occurrence of criminal behaviour. After reviewing sufficient literature need was felt to find out the relation between dysfunction in the specific areas of brain and risk of criminal behaviour as biopsychosocial perspectives will help in preventing the risk of criminal behaviour and planning intervention accordingly.

METHODOLOGY

Purpose of the Study: To study the neuropsychological profile of Juvenile delinquents.

Research Design: Purposive sampling technique was used in this study. 


\section{Neuropsychological Profile of Juvenile Delinquents}

Sample: Juvenile delinquents who have committed repeated offences between the ages 10 to 14 years, male gender with minimum primary education was selected using Purposive Sampling Technique. 15 cases were selected from Observation Home (Baal Sudhar Grah), Hardoi Road, Lucknow.

The sample was selected based on the following inclusion and exclusion criterion.

\section{Inclusion Criteria}

- Juvenile delinquents who have committed repeated offences

- Children between the ages of 10 to 14 years.

- Children of the male gender.

- Children with minimum primary education.

- Children falling between Grade 1 to 3 on either Color Progressive matrices or Standard Progressive matrices.

- Children getting a score of 3 and above in all of the subtests of Diagnostic Test of Learning Disability.

- Children scoring less than 11 on Brief Psychiatric Rating Scale-Children

\section{Exclusion Criteria}

- Juvenile Delinquents with first offences.

- Children below the 10 years of age and above 14 years of age.

- Children of the female gender.

- Children with less than primary education.

- Children falling in Grade 4 or 5 either on Color Progressive Matrices or Standard Progressive Matrices.

- Children getting the score below 3 in any of the subtests of Diagnostic Test of Learning Disability.

- Children with any Psychiatric illness.

\section{Measures}

Following tools were used to screen the presence of any psychiatric illness, Learning Disability and IQ below the normal range.

\section{COLOURED PROGRESSIVE MATRICES / STANDARD PROGRESSIVE}

MATRICES: This was used as a screening tool. It is a nonverbal group test typically used in educational settings developed by John C. Raven in 1938. It is usually a 60-item test used in measuring abstract reasoning and regarded as a non-verbal estimate of intelligence. It is the most common and popular test administered to groups ranging from 5-year-olds to the elderly. Most items are presented on a coloured background to make the test visually stimulating for participants. Coloured Progressive Matrices consists of three sets, A, Ab and B and Standard Progressive Matrices consists of 5 sets A, B, C, D and E. The raw score is converted into percentiles from the norms table and they should lie on the Grade 1 to 3 i:e Intellectually average above 25 thpercentile. The reliability coefficient of the test is .63 and .89 (Raven, 1938)

DIAGNOSTIC TEST OF LEARNING DISABILITY: This was used as a screening tool which was developed by Smriti Swarup and Dharmishta H. Mehta. It was used to identify those children, who experience learning problems, because of learning disability. It consists of 10 subtests, Eye-Hand Coordination, Figure-Ground Perception, Figure Constancy, and Position in Space, Spatial Relations, Auditory Perception, Memory, Cognitive Abilities, 
Receptive Language and Expressive Language. It is to be individually administered on the age group 8-11 years of age as it is used for only the purpose of screening the age range was not followed (supportive researches were studied where it is used for children above the age range). A score of 3 or less than 3 in any subtests is indicative of learning disability. It is reliable and valid, the reliability coefficient is 0.87 (Mehta \& Swarup, 2004).

BRIEF PSYCHIATRIC RATING SCALE: The Brief Psychiatric Rating Scale for Children (BPRS-C) was used as a screening tool which a clinician or researcher may use to measure psychiatric symptoms such as depression, anxiety, hallucinations and unusual behaviour. It was developed by Pfefferbaum B. There are a total of 21 items rating scale that provides a descriptive profile of child and adolescent psychopathology. Ratings are based on a 7 point Likert Scale, from, "Not present" to "Extremely Severe". A score of 11 or more than 11 indicates the presence of psychiatric disorder (Overall, J.E., \& Pfefferbaum, B., 1982).

\section{Study Tool}

AIIMS COMPREHENSIVE NEUROPSYCHOLOGICAL BATTERY FOR CHILDREN: This was used as the main tool for neuropsychological profiling. This test battery is used to assess cognitive functions among the subjects. Prof. Surya Gupta and others constructed this battery (AIIMS, 1998). It contains information on the patient's cognitive functioning capability related to reading, writing, arithmetic, and memory, intelligence skills together with expressive speech, receptive speech capabilities, and motor functions. Test-retest reliability is 0.957 . The battery consists of 135 items spread over 10 scales measuring skill areas: motor, tactile, visual, receptive, speech, expressive speech, reading, writing, arithmetic, memory and intellectual processes (Gupta S, 2000).

\section{Procedure}

Potential participants were selected based on the Inclusion and Exclusion criterion mentioned above from Observation Home using Purposive Sampling Technique. The purpose of the study was explained to them and written informed consent was sought. Then screening tools were administered. Children were screened through the Brief Psychiatric Rating Scale to assess the presence of psychiatric disorder. The diagnostic tool of learning disability was administered to screen out learning disability. Coloured Progressive Matrices or Standard Progressive Matrices was administered to screen the individuals with subaverage intelligence. Finally, participants of the study $(n=15)$ were selected and AIIMS Neuropsychological battery was administered on them to assess the neuropsychological functioning of the children. Appropriate statistics were used for the interpretation of data to form neuropsychological profiles.

\section{RESULTS}

Table showing AIIMS Neuropsychological battery total scores for the study cases $(n=15)$ Table 1 AIIMS Neuropsychological Battery Final score

\begin{tabular}{|c|c|c|c|c|c|}
\hline & Frequency & Percent & Valid Percent & Cumulative Percent \\
\hline \multirow[t]{3}{*}{ Valid } & $\begin{array}{l}\text { Organicity Not } \\
\text { Present }\end{array}$ & 3 & 20.0 & 20.0 & 20.0 \\
\hline & Organicity Present & 12 & 80.0 & 80.0 & 100.0 \\
\hline & Total & 15 & 100.0 & 100.0 & \\
\hline
\end{tabular}




\section{Neuropsychological Profile of Juvenile Delinquents}

The above-mentioned TABLE 1 is representing AIIMS neuropsychological battery total scores wherein Organicity was found to be present in 12 cases that is $80 \%$ of the total cases. Organicity is not present in 3 cases that is $20 \%$ of the total cases.

Summary of Frequency and Percentages for All Subscales of AIIMS Neuropsychological Battery for The Study Cases $(N=15)$.

Table 2

\begin{tabular}{|c|c|c|c|}
\hline Subscales & Frequency & $\begin{array}{l}\text { Organicity } \\
\text { Present }\end{array}$ & $\begin{array}{l}\text { Organicity Not } \\
\text { Present }\end{array}$ \\
\hline Motor & 15 & $100 \%$ & $0 \%$ \\
\hline \multirow[t]{2}{*}{ Tactile } & 11 & $73.3 \%$ & \\
\hline & 4 & & $26.7 \%$ \\
\hline Visual & 15 & $100 \%$ & $0 \%$ \\
\hline \multirow[t]{2}{*}{ Receptive } & 7 & $46.7 \%$ & \\
\hline & 8 & & $53.3 \%$ \\
\hline \multirow[t]{2}{*}{ Expressive } & 7 & $46.7 \%$ & \\
\hline & 8 & & $53.3 \%$ \\
\hline \multirow{2}{*}{ Reading } & 7 & $46.7 \%$ & \\
\hline & 8 & & $53.3 \%$ \\
\hline \multirow{2}{*}{ Writing } & 9 & $60 \%$ & \\
\hline & 6 & & $40 \%$ \\
\hline \multirow[t]{2}{*}{ Arithmetic } & 12 & $80 \%$ & \\
\hline & 3 & & $20 \%$ \\
\hline \multirow[t]{2}{*}{ Memory } & 14 & $93.3 \%$ & \\
\hline & 1 & & $6.7 \%$ \\
\hline \multirow[t]{2}{*}{ Intellectual } & 1 & $6.7 \%$ & \\
\hline & 14 & & $93.3 \%$ \\
\hline \multirow[t]{2}{*}{ Pathogonomic } & 12 & $80 \%$ & \\
\hline & 3 & & $20 \%$ \\
\hline \multirow[t]{2}{*}{ Left Hemisphere } & 12 & $80 \%$ & \\
\hline & 3 & & $20 \%$ \\
\hline \multirow[t]{2}{*}{ Right Hemisphere } & 13 & $86.7 \%$ & \\
\hline & 2 & & $13.3 \%$ \\
\hline
\end{tabular}

$100 \%$ of participants showed presence of organicity in Motor and Visual whereas in Intellectual, Receptive, Expressive and Reading Scale organicity was not found to be present.

\section{DISCUSSION}

The aim of the current research was to assess the Neuropsychological Profile of Juvenile Delinquents. Previous researches have suggested that the frontal lobe of the human brain controls systems that implement a variety of different behavioural strategies in response to the environment (Kolb \& Whishaw, 2008). Some studies suggest that frontal lobe functions may also control emotional responses such as regulation of emotions, aggression, and antisocial personality traits (Bauer, O’Connor, \& Hesselbrock, 1994; Yeudall \& FrommAuch, 1979). Biosocial perspectives help illuminate the link between biological influences, social and environmental influences, which in turn drives the realization that viewing crime as a response to a multitude of risk factors. A multi-faced approach, therefore, is recommended when examining the potential for new policies and practices designed to

(c) The International Journal of Indian Psychology, ISSN 2348-5396 (e)| ISSN: 2349-3429 (p) | 65 
address crime, especially when taking into account the summarized findings present herein. Though there are various situations and factors that contributed to the occurrence of the crime, the brain plays a major role in determining a plan of action during that particular situation. Individual who is not able to control his plan of action in an appropriate manner has more chances to commit an act which are not acceptable socially and morally therefore to understand the action taken by the individual at the time of committing a crime it is important to understand the neuropsychological aspects of it in order to prevent crime or plan intervention for juveniles. 15 cases who have committed repeated offences, between age group 10 to 14 of the male gender with minimum primary education were selected using Purposive Sampling technique from Baal Sudhar Grah, Lucknow. They were screened through Diagnostic Test of learning disability, Colored Progressive Matrices/Standard progressive Matrices and Brief Psychiatric Rating Scale for Children. Samples with IQ below sub-average, learning disability or any kind of psychopathology were excluded from the study. AIIMS neuropsychological battery was administered to assess the neuropsychological functioning of the delinquents. Result reveals that organicity was found to be present in 12 cases that is $80 \%$ of the total cases whereas organicity is not present in 3 cases that is $20 \%$ of the total cases (as shown in Table 1). In specific areas it was found that $100 \%$ of participants showed the presence of organicity in Motor and Visual, followed by Memory 90\%, Right Hemisphere Scale 85\%, Left Hemisphere and Pathognomonic Scale $80 \%$, Arithmetic $80 \%$, Tactile $75 \%$ and Writing $60 \%$ whereas in Intellectual, Receptive, Expressive and Reading Scale organicity was not found to be present (as shown in Table 2 ). Dysfunction in Motor Scale indicates that the basic motor coordination, imitation and construction skills of the delinquents are impaired. In the Study conducted by Tung and Chhabra (2009) they attempt to differentiate the delinquents from non-delinquent by using neuropsychological measures for study purpose of early identifications of neuropsychological parameters in children to prevent delinquent outcomes. The neuropsychological examination of both groups was carried out by administering the Standard Progressive test, Bender Gestalt Test, Stroop Color and Word Test. Their findings made it clear that the neuropsychological status of delinquents differs from that of nondelinquents. The results have implications of planning proper prevention programs for vulnerable children at an early age. The visual scale measures simple visual recognition of actual objects as well as pictures, visual recognition of non-visual or shaded figures, recognition of multiple objects, comparison of rotated figures, visual memory and recognition of visual special functions, therefore, dysfunction in visual scale is indicative of the above mentioned functioned as impaired. Tarnopol, Lester. (1970), studied the relation between Delinquencies and minimal brain dysfunction in which result indicates that there will be the small proportion of the visual-motor problem related to disturbances of visual perception and chances to lead to minimal brain dysfunction in children. Recent, remote, verbal and nonverbal memory is also found to be impaired. Pathognomonic Scales are indicative of extremely difficult items for brain damage children so the dysfunction in this scale is indicative of brain damage. Left and Right Hemisphere Scale are capable to indicate the laterality of damage in the brain of a child. Teichner, G., et al. studied the Patterns of neuropsychological functioning in a sample of conduct disordered youth administered by neuropsychological assessment the Luria Nebraska Neuropsychological battery. The Findings were found to be significantly deficit in Verbal/Left hemisphere, Subcortical Frontal. Findings were significant with an abnormal range that is differed per subtype that each subtype is differing from one another. Dysfunction in writing scale is indicative of problems in analyzing letter sequences, to spell to copy and to write from dictation. Results are indicative of problems in number recognition, number writing and number recognition because of the dysfunction of Arithmetic scale. Svenson, Lundberg, Jacobson et al. (2001) 


\section{Neuropsychological Profile of Juvenile Delinquents}

conducted the study to estimate the prevalence of reading and writing disabilities in juvenile institutions. 163 Pupils from 22 institutions participated in the study and results revealed that more than $70 \%$ showed some problems in reading and spelling. However, only $11 \%$ had serious difficulties.

Dysfunction in the tactile scale is suggestive of an impaired finger, arm localization and shape discrimination. Galski, T., Thornton, K. E., \& Shumsky, D. (1990), conducted the study to evaluate the brain dysfunction in sexual offenders using the measures of Luria Nebraska Neuropsychological battery for the purpose of neuropsychological investigations. Findings suggested that the brain impairment has been linked to the pathogenesis of sexual disorders and aberrations specifically related to the impaired functioning in tactile scale. On the basis of the above results and interpretation, it can be concluded that in Neuropsychological Profiles of Juvenile Delinquents impairments can be seen in many functional areas of the brain. The findings of the present research can be implied by making teachers, parents and mental health professionals aware of the fact that children having neuropsychological impairment are at risk of indulging into criminal behaviour. This knowledge would in turn help the parents and teachers of such children to monitor their behaviour as well as provide proper intervention.

The children who have already committed a crime can also be assessed for the presence of neuropsychological impairment so that proper intervention can be planned for them. There were a few limitations of the present research. First of all this research was conducted on a small sample size and at only one place. Therefore, to generalize the results the study should have involved more participants at different levels. Secondly, this research was conducted on only male children so differences between neuropsychological profiles of male and female children could not be found. In addition, since there was no control group in the study therefore differences in the neuropsychological profiles of delinquents and nondelinquents could not be elicited.

\section{CONCLUSION}

On the basis of above results and interpretation it can be concluded that hypothesis that is Neuropsychological Profiles of Juvenile Delinquents will be impaired is accepted. Out of 15 samples, organicity was present in 12 of them, whereas in three of the samples organicity was absent. Presence of organicity is $80 \%$ and the absence is $20 \%$. In the Subscale of AIIMS Motor and Visual is showing $100 \%$ of Organicity, followed by Memory $90 \%$, Right Hemisphere Scale 85\%, Left Hemisphere and Pathognomonic Scale 80\%, Arithmetic 80\%, Tactile 75\% and Writing 60\% whereas in Intellectual, Receptive, Expressive and Reading Scale the percentage of Organicity not present is more than that of Organicity present which is in coherence with the previous research findings or review of literatures.

\section{REFERENCES}

Galski, T., Thornton, K. E., \& Shumsky, D. (1990). Brain dysfunction in sex offenders. Journal of Offender Rehabilitation, 16(1-2), 65-80.

Graham Beaumont. (2008). Introduction to Neuropsychology IInd edition. The Guildford Press.

Gupta S, Khandelwal SK, Tandon PN, Maheshwari MC, Mehta VS, Sundram KR, et al. The development and standardization of a comprehensive neuropsychological battery in Hindi children form. J Pers Clin Stud 200; 16:75-109. 
Johnson, V. A., Kemp, A. H., Heard, R., Lennings, C. J., \& Hickie, I. B. (2015). Childhoodversus adolescent-onset antisocial youth with conduct disorder: psychiatric illness, neuropsychological and psychosocial function. PloS one, 10(4), e 0121627.

Mehta, D.H., \& Swarup, S. (2004). The Diagnostic Test of Learning Disability (DTLD). Asia Pacific Disability Rehabilitation Journal, 15(1), 50-58.

Moffitt, T. E., \& Henry, B. (1989). Neuropsychological assessment of executive functions in self-reported delinquents. Development and Psychopathology, 1(2), 105-118

Moffitt, T. E., \& Henry, B. (1991). Neuropsychological studies of juvenile delinquency and juvenile violence. In Neuropsychology of aggression (pp. 67-91). Springer, Boston, $M A$.

Overall, J. E., \& Pfefferbaum, B. (1982). The Brief Psychiatric Rating Scale for Children. Psychopharmacology Bulletin, 18(2), 10.

Raven, J.C. (1938). Raven's progressive matrices. Western Psychological Services.

Reichenberg A. A. (2010). The assessment of neuropsychological functioning in scizophernia. Dialogues in clinical neuroscience, 12(3), 383.

Svensson, I., Lundberg, I., \& Jacobson, C. (2001). The prevalence of reading and spelling difficulties among inmates of institutions for compulsory care of juvenile delinquents. Dyslexia, 7(2), 62-76.

Tarnopol, Lester. "Delinquency and minimal brain dysfunction." Journal of Learning Disabilities 3.4 (1970): 200-208.

Teichner, G., Crum, T. A., Golden, C. J., Azrin, N. H., \& Donohue, B. (1999). Patterns of neuropsychological functioning in a sample of conduct disordered youth. Archives of Clinical Neuropsychology, 14(1), 21-21.

Tung, S., \& Chhabra, N. (2011). A comparative study on the neuropsychological status of delinquent and non-delinquent boys. International Journal of Culture and Mental Health, 4(2), 121-127.

\section{Acknowledgement}

The author(s) appreciates all those who participated in the study and helped to facilitate the research process.

\section{Conflict of Interest}

The author(s) declared no conflict of interest.

How to cite this article: Sahoo S. N., Srivastava R. \& Baveja D. (2021). Neuropsychological Profile of Juvenile Delinquents. International Journal of Indian Psychology, 9(2), 61-68. DIP:18.01.009.20210902, DOI:10.25215/0902.009 